\title{
Communicating Hydrocephalus and Dementia
}

\author{
Ali Mahmood Khan ${ }^{1 *}$, Shahzaib M Khan², Muhammad Mustafa Ahmed ${ }^{2}$, Nimisha Srivastava ${ }^{3}$ \\ ${ }^{1}$ Kings County Hospital Center, USA \\ ${ }^{2}$ Ziauddin Medical College, Pakistan
}

${ }^{3}$ Kasturba Medical University, India

Submission: July 19, 2017; Published: July 24, 2017

*Corresponding author: Ali Mahmood Khan, Kings County Hospital Center, USA; Tel: 408838 1189;Email: ali_mahmood_khan@hotmail.com

\begin{abstract}
This case is of a 52 year old single woman with memory problems. CT scan reveals communicating hydrocephalus and MRI seen by neuroradiology deems it to be a chronic process. Patient is HIV negative. Has a steady gait and can go to the bathroom on her own. In CPEP she had auditory and visual hallucinations. Was fairly oriented to self but could not tell minute details such as age or date of birth. Has had only one inpatient psychiatric admission in the past 5 years and prescribed Sertraline $50 \mathrm{mg}$ in June 2016 by a psychiatrist. She was also on Citalopram $10 \mathrm{mg}$ in 2014 and Trazodone 50mg in 2014. Patient has no history of drugs or intoxication or any sort of emotional, mental or physical abuse.
\end{abstract}

\section{Introduction}

This research is being conducted to find out the relationship between communicating hydrocephalus and dementia. According to previous researches there is scarce evidence to find a relationship in between the two, but certain researches state that communicating hydrocephalus is a cause of dementia. This research will go into further detail to investigate whether there is any relation between the two or not.

\section{Case Presentation}

The patient is a single 52 year old woman. With ambiguity regarding her living arrangement and as to how she supports herself. Patient is a very poor historian. On CT scan patient has a communicating hydrocephalus. MRI was seen by neuroradiology and deemed it to be a chronic process possibly due to a remote meningitis or HIV (she is HIV-) and that it is not reflective of her current psychiatric symptoms. She has a steady gait, goes go to the bathroom often, but has no incontinence. In the CPEP she had auditory and visual hallucination, but on the unit she denied them. She was only oriented to self, but could not tell us her age or the year she was born. As per social worker the patient was prescribed Sertraline 50mg in June 2016 by her Psychiatrist. She was also on Citalopram $10 \mathrm{mg}$ in 2014 and Trazodone 50mg in 2014. She has only had one in-patient psychiatry admission in the past 5 years, from $1 / 1 / 16-8 / 4 / 16$." The patient shows no signs of intoxication or withdrawal to any substance and denies use of any substance abuse in the past.Additionally patient thinks that she has been here for 2 years, while in reality she has been on the unit for only 45 days.

Patient has evidence of a formal thought process disorder [disorganization], has poor memory, concentration, and attention. Denies auditory/visual/tactile/olfactory hallucinations, depression, and signs of mania. Patient's sleep and appetite are within normal limits. Patient denies thoughts, urges, intent, or plan to harm self or others at this time. Patient does not report physical, sexual, or emotional abuse at present. Patient reports no alcohol, cigarette, or drug abuse. Patient reports no episodes of self-harming behavior. Patient has not been able to take care of her ADLs and therefore it's recommended that patient should be discharged to an assisted living facility.

On mental status evaluation the patient's insight is poor; Judgment is impaired; Attention Span is poor by interview; Memory is impaired (grossly impaired on interview, 2/3 recall immediately, 0/3 recall at 5 minutes, named "pen" \& "watch", could not spell "world" backwards); Intellectual Functioning is Impaired; MOCA score 3/30 obtained on 3/15/17.

Patient is currently being prescribed Escitalopram PO $20 \mathrm{mg}$ QAM for depressed mood and Methylphenidate $5 \mathrm{mg}$, PO, BID. According to the neurologist and neuropsychiatrist the patient is so far gone in terms of dementia that she has not been started 
on any anticholinergic medication as they think that starting the medication now will not do her any good. Patient has been previously treated with trials of anticholinergic medication to no avail (Figure 1).

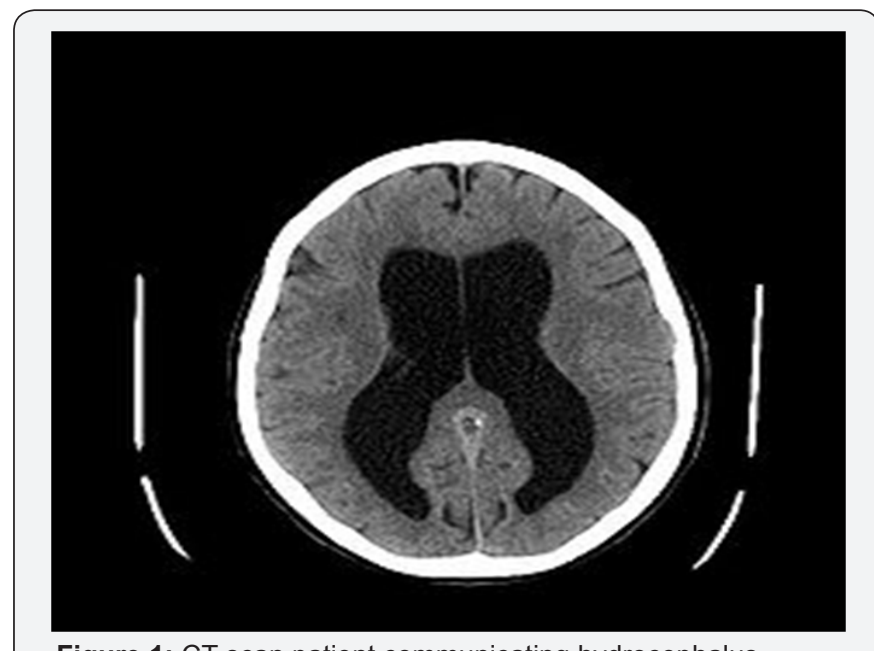

Figure 1: CT scan patient communicating hydrocephalus.

\section{Discussion}

Hydrocephalus is an excessive accumulation of cerebrospinal fluid in the brain. This accumulation results in widening of the ventricles within the brain which creates excessive pressure [1]. Hydrocephalus may be congenital or acquired. It is furthermore divided as communicating and non-communicating. Communicating hydrocephalus is when cerebrospinal fluid is blocked after leaving the ventricles and in non-communicating hydrocephalus, also known as obstructive hydrocephalus, there is a blockage in the lushkas between the ventricles [2].

Dementia is a general term for decline in mental ability that is severe enough to interfere with daily life things like memory, language, communication and visual perception. Alzheimer's disease is the most common form of dementia [3]. Other types of dementia include vascular dementia, dementia with Lewy bodies, mixed dementia, Parkinson's disease, etc. Dementia is most commonly caused by trauma to the head, strokes or other factors that lead to brain injuries [4].

According to a few researches conducted, communicating hydrocephalus has found to be a cause of dementia. It is also fairly easy to understand that dementia is caused by trauma to the cranial cavity [5]. Since communicating hydrocephalus causes a block after leaving the ventricles, it increases theintracranial pressure which results in trauma to the brain [6]. This trauma can cause dementia. Isotope encephalography and air encephalography have been used to investigate patients with progressive dementia according to certain researches. Communicating hydrocephalus was observed in 8 out of the 14 patients that were studied [7].

Researchers have also been conducted where patients are non-invasively screened via CT scans who are suffering from presenile dementia and the results of the CT scans show hydrocephalus [8]. Some patients also suffered from treatable dementia that led to patients suffering from hydrocephalus [9]. Therefore if dementia is diagnosed earlier and treated, the cases of hydrocephalus occurring due to dementia will certainly decrease. It can also be stated that it is not a new discovery, as there has been previous researches back in time where communicating hydrocephalus and dementia have been found to be common in patients. According to a research conducted, 5 patients had communicating hydrocephalus and one case had colloid cyst of the 3rd ventricle. All patients presented with similar clinical findings which included psychomotor retardation and dementia. The triad of dementia, gait disorder and urinary incontinence was especially constant in all features. Therefore it is safe to say that there is a strong relationship between the two diseases [10].

\section{Conclusion}

After research it can be concluded that there is a relationship in between communicating hydrocephalus and dementia [3]. Patients having communicating hydrocephalus have also been observed to have a certain degree of dementia as well. Hence it can be stated that there is a positive relationship in between communicating hydrocephalus and dementia $[1,8]$.

\section{References}

1. Coblentz JM, Mattis S, Zingesser LH, Kasoff SS, Wiśniewski HM, et al. (1973) Presenile dementia clinical aspects and evaluation of cerebrospinal fluid dynamics. Arch Neurol 29(5): 299-308.

2. Chawla JC, Hulme A, Cooper R (1974) Intracranial pressure in patients with dementia and communicating hydrocephalus. J Neurosurg 40(3): 376-380.

3. Frank Noronha (1925) A Case of Unilateral Hydrocephalus. The British Journal of Psychiatry 71 (295): 729-730.

4. S O'Flaithbheartaigh, PA Williams, GH Jones (1994) Schizophrenic psychosis and associated aqueduct stenosis. The British Journal of Psychiatry 164 (5): 684-686.

5. Nagata Y, Bundo M, Sugiura S, Kamita M, Ono M, et al. (2017) PTPRQ as a potential biomarker for idiopathic normal pressure hydrocephalus. Mol Med Rep.

6. Ahmed HMA, El-Gohary R, Fayed F, El-Gendy H (2017) Cerebellar ataxia and obstructive hydrocephalus, rare neurologic presentations in patients with systemic lupus erythematosus. Rheumatol Int.

7. Roger Bannister, Roman Kocen (1967) Isotope Encephalography in the Diagnosis of Dementia Due to Communicating Hydrocephalus. The Lancet 2(7524): 1014-1017.

8. HA Crockard, Kathryn Hanlon, EE Duda, JF Mullan (1977) Hydrocephalus as a cause of dementia: evaluation by computerised tomography and intracranial pressure monitoring. J Neurol Neurosurg Psychiatry 40(8): 736-740.

9. GC Victoratos, JA Lenman, L Herzberg (1977) Neurological investigation of dementia. The British Journal of Psychiatry 130(2): 131-133.

10. Tator CH, Murray S (1971) A clinical, pneumoencephalographic and radioisotopic study of normal-pressure communicating hydrocephalus. Can Med Assoc J 105(6): 573-579. 
(C) This work is licensed under Creative

(CC) DOI: 10.19080/PBSIJ.2017.4.555650
Your next submission with JuniperPublishers will reach you the below assets

- Quality Editorial service

- Swift Peer Review

- Reprints availability

- E-prints Service

- Manuscript Podcast for convenient understanding

- Global attainment for your research

- Manuscript accessibility in different formats

( Pdf, E-pub, Full Text, Audio)

- Unceasing customer service

Track the below URL for one-step submission https://juniperpublishers.com/online-submission.php 